\title{
NKI05, a paclitaxel-incorporating micellar nanoparticle, is a more potent radiosensitising agent compared to free paclitaxel
}

\author{
T Negishi', F Koizumi', H Uchino², J Kuroda', T Kawaguchi', S Naito² and Y Matsumura*,I \\ 'Investigative Treatment Division, Research Center for Innovative Oncology, National Cancer Center Hospital East, 6-5-I Kashiwanoha, Kashiwa, Chiba \\ 277-8577, Japan; ${ }^{2}$ Department of Urology, Graduate School of Medical Sciences, Kyushu University, 3-I-I Maidashi, Higashi-ku, Fukuoka, Fukuoka \\ 81 2-8582, Japan; ${ }^{3}$ Department of Anatomy and Histology, Fukushima Medical University School of Medicine, I-Hikariga-oka, Fukushima, Fukushima \\ 960-1247, Japan
}

NKI05 is a micellar nanoparticle formulation designed to enhance the delivery of paclitaxel (PTX) to solid tumours. It has been reported to exert antitumour activity in vivo and to have reduced neurotoxicity as compared to that of free PTX. The purpose of this study was to investigate the radiosensitising effect of NKIO5 in comparison with that of PTX. Lewis lung carcinoma (LLC)-bearing mice were administered a single intravenous (i.v.) injection of PTX or NK I05; $24 \mathrm{~h}$ after the drug administration, a proportion of the mice received radiation to the tumour site or lung fields. Then, the antitumour activity and lung toxicity were evaluated. In one subset of mice, the tumours were excised and specimens were prepared for analysis of the cell cycle distribution by flow cytometry. Combined NK 05 treatment with radiation yielded significant superior antitumour activity as compared to combined PTX treatment with radiation $(P=0.0277)$. On the other hand, a histopathological study of lung sections revealed no significant difference in histopathological changes between mice treated with PTX and radiation and those treated with NKI05 and radiation. Flowcytometric analysis showed that NKI05-treated LLC tumour cells showed more severe arrest at the G2/M phase as compared to PTX-treated tumour cells. The superior radiosensitising activity of NK 105 was thus considered to be attributable to the more severe cell cycle arrest at the G2/M phase induced by NKI 05 as compared to that induced by free PTX. The present study results suggest that further clinical trials are warranted to determine the efficacy and feasibility of combined NKI05 therapy with radiation.

British Journal of Cancer (2006) 95, 60 I-606. doi: I0.1038/sj.bjc.66033 I I www.bjcancer.com

Published online 8 August 2006

(c) 2006 Cancer Research UK

Keywords: paclitaxel; NKI05; radiosensitiser; polymer micelle; drug delivery system

Paclitaxel (PTX) has been demonstrated to be one of the most effective anticancer agents available at present (Carney, 1996; Khayat et al, 2000). Besides its antitumour activity, its ability to induce radiosensitisation has been reported both in vitro (Tishler et al, 1992; Choy et al, 1993; Lokeshwar et al, 1995; Rodriguez et al, 1995) and in vivo (Milas et al, 1994, 1995; Cividalli et al, 1998) this effect has been attributed to its effect of stabilising microtubules and inducing cell cycle arrest at the G2/M phase, the most radiosensitive phase of the cell cycle (Terasima and Tolmach, 1963; Sinclair and Morton, 1966). As several clinical studies have demonstrated the efficacy of PTX-based chemotherapy combined with radiotherapy, the combined modality is considered to be a potentially important treatment option for lung and breast cancer (Choy et al, 1998a, b, 2000; Dowell et al, 1999; Formenti et al, 2003; Kao et al, 2005).

The adverse effects of radiation, namely, lung toxicities in patients with breast or lung cancer treated by thoracic radiation, are of great concern, and may be dose limiting or even have a negative impact on the quality of life of the patients, even though radiation is an efficient treatment option. Lung toxicities often

*Correspondence: Dr Y Matsumura; E-mail: yhmatsum@east.ncc.go.jp Revised 5 June 2006; accepted II July 2006; published online 8 August 2006 result in lung fibrosis, necessitating change of the treatment method and causing much distress or even death of the patients (Penney and Rubin, 1977; Early Breast Cancer Trialists' Collaborative Group, 2000; Lind et al, 2002). Some clinical trials actually reported an increased incidence of pneumonitis following combined PTX therapy with radiation in patients with breast or lung cancer (Taghian et al, 2001; Hanna et al, 2002; Chen and Okunieff, 2004).

Although widely used, PTX itself has several adverse effects, such as peripheral sensory neuropathy (Rowinsky et al, 1993; Rowinsky and Donehower, 1995), and its poor solubility in water is also associated with such effects as anaphylaxis and other severe hypersensitivity reactions attributable to Cremophor EL and ethanol, which are essential for solubilising PTX (Weiss et al, 1990; Rowinsky and Donehower, 1995). In order to overcome these problems, we prepared a new formulation, NK105, which is a PTXincorporating polymeric micellar nanoparticle $(85 \mathrm{~nm}$ in size) (Hamaguchi et al, 2005). NK105 is formed by facilitating the self-association of amphiphilic block copolymers constructed using polyethylene glycol (PEG) as the hydrophilic segment and modified polyaspartate as the hydrophobic segment in an aqueous medium. Owing to the PEG constituting the outer shell of the micelles, NK105 is soluble in water. In addition, PEG also confers a stealth property to the formulation, that allows the micellar drug preparation to be less avidly taken up by the reticuloendothelial 
602

system (RES) and to be retained in the circulation for a longer period of time (Klibanov et al, 1990, 1991; Allen, 1994; Gabizon et al, 1996). The prolonged circulation time and the ability of NK105 to extravasate through the leaky tumour vasculature (i.e., the EPR (enhanced permeability and retention) effect) causes accumulation of PTX in tumour tissues (Matsumura and Maeda, 1986; Maeda and Matsumura, 1989). We previously demonstrated that NK105 is associated with reduced neurotoxicity and also exerts more potent antitumour activity on human cancer xenograft, as compared to free PTX. In addition, because of its solubility in water, it is expected that the incidence of anaphylaxis and hypersensitivity reactions attributable to Cremophor EL and ethanol may also be reduced with NK105. A clinical trial of NK105 is now under way.

In this context, it is expected that the use of NK105 in place of PTX in combination with radiation may also yield superior results, because of the more potent antitumour activity of this drug as compared to that of free PTX. In this study, we evaluated the antitumour activity and severity of lung fibrosis induced by PTX and NK105 administered in combination with thoracic radiation, to examine whether combined NK105 chemotherapy with radiation would be an acceptable or useful treatment modality.

\section{MATERIALS AND METHODS}

\section{Mice}

Eight-week-old female C57BL/6J mice were purchased from Charles River Japan Inc. (Kanagawa, Japan). All the animal procedures were performed in compliance with the guidelines for the care and use of experimental animals, drawn up by the Committee for Animal Experimentation of the National Cancer Center; these guidelines meet the ethical standards required by law and also comply with the guidelines for the use of experimental animals in Japan.

\section{PTX and NK105}

Paclitaxel was purchased from Merican Corp. (Tokyo, Japan). NK105 is a PTX-incorporating 'core-shell-type' polymeric micellar nanoparticle formulation that was prepared by a previously reported procedure (Hamaguchi et al, 2005). Briefly, polymeric micellar particles were formed by facilitating the self-association of amphiphilic block copolymers in an aqueous medium. The polymer of NK105 was constructed using PEG as the hydrophilic segment and modified polyaspartate as the hydrophobic segment. The carboxylic groups of the polyaspartate block were modified by the esterification reaction with 4-phenyl-1-butanol, resulting in conversion of half of the groups to 4-phenyl-1-butanolate. Molecular weight of the polymers was determined to be approximately 2000 (PEG block: 12 000; moditied polyaspartate block: 8000).

Via the self-association process, PTX was incorporated into the inner core of the micelle system by physical entrapment through hydrophobic interactions between the drug and specifically welldesigned block copolymers for PTX. NK105 was obtained as a freeze-dried formulation and contained ca.23\% $\left(\mathrm{WW}^{-1}\right)$ of PTX. Finally, NK105, PTX-incorporating polymeric micellar nanoparticle formulation with a single and narrow size distribution, was obtained. The weight-average diameter of the nanoparticles was approximately $85 \mathrm{~nm}$ ranging from 20 to $430 \mathrm{~nm}$.

\section{Irradiation}

The mice were anesthetised by intraperitoneal (i.p.) injection of nembutal $\left(75 \mathrm{mg} \mathrm{kg}^{-1}\right)$ and placed on the stage for irradiation. The whole thorax or subcutaneous (s.c.) tumours of the thigh were irradiated using a Faxitron cabinet X-ray system model CP-160 by
$100 \mathrm{kV}$ X-rays from a linear accelerator, at a dose rate of $2 \mathrm{~Gy} \mathrm{~min}^{-1}$. Totally $12 \mathrm{~Gy}$ was irradiated to each mouse. The whole body except irradiated parts, lung field or tumour lesion, were shielded with specially designed lead blocks.

\section{Flow cytometry}

At $24 \mathrm{~h}$ after the injection of PTX or NK105 into the Lewis lung carcinoma (LLC) tumour-bearing C57BL/6j mice, the tumours were excised, minced in PBS, and fixed in $70 \%$ ethanol at $4{ }^{\circ} \mathrm{C}$ for $48 \mathrm{~h}$. After being fixed, the tumours were digested with $0.04 \%$ pepsin (Sigma chemical co., St Louis, MO, USA) in $0.1 \mathrm{~N} \mathrm{HCl} \mathrm{for}$ $60 \mathrm{~min}$ at $37^{\circ} \mathrm{C}$ in a shaking bath for preparing single-nuclei suspensions. The nuclei were then centrifuged, washed twice with PBS, and stained with $40 \mu \mathrm{g} \mathrm{ml}^{-1}$ of propidium iodide (Molecular Probes, OR, USA) in the presence of $100 \mu \mathrm{g} \mathrm{ml}^{-1}$ RNase in $1 \mathrm{ml}$ PBS for $30 \mathrm{~min}$ at $37^{\circ} \mathrm{C}$. The stained nuclei were analysed with a B-D FACSCalibur (BD Biosciences, San Jose, CA, USA). The cell cycle distribution was analysed using the Modfit program (Verity Software House Inc., Topsham, ME, USA).

\section{Evaluation of the antitumour activity}

For this experiment, $3 \times 10^{6} \mathrm{LLC}$ cells were inoculated s.c. into the right thighs of mice. The tumour volume was calculated using the formula, tumour volume $\left(\mathrm{mm}^{3}\right)=a \times b^{2} / 2 \quad(a=$ longest tumour diameter, $b=$ shortest tumour diameter). When the tumour volume reached approximately $100 \mathrm{~mm}^{3}$ on day 14 after the tumour inoculation, the mice were randomly allocated to test groups of about four or five mice each, and started the treatment on the same day. There were six test groups, as follows: untreated control, PTX treatment alone, NK105 treatment alone, radiation alone, combined PTX treatment with radiation, and combined with NK105 treatment with radiation.

In the groups receiving PTX or NK105, the mice were administered a single intravenous (i.v). injection of PTX or NK105 at the dose of $45 \mathrm{mg} \mathrm{kg}^{-1} ; 24 \mathrm{~h}$ after the drugs were administered, the tumour sites of the mice in the groups scheduled to receive radiation were irradiated.

The antitumour activity of each treatment regimen was evaluated by measuring the tumour volume. Tumour volume and body weight was measured every 3 days.

\section{Evaluation of lung toxicity}

The severity of lung toxicity was evaluated histologically in the following test groups; untreated control $(n=6)$, radiation treatment alone $(n=6)$, combined PTX treatment with radiation $(n=9)$, and combined NK105 treatment with radiation $(n=10)$. Mice were administered a single i.v. injection of PTX or NK105 at the dose of $45 \mathrm{mg} \mathrm{kg}^{-1} ; 24 \mathrm{~h}$ after the drugs were administered, the thorax of the mice in the groups scheduled to receive radiation was irradiated. All the mice were killed 36 weeks after the drug administration. At the time of the killing, the lungs were removed, and the right lungs were fixed in $10 \%$ buffered formalin for $24 \mathrm{~h}$, then embedded in paraffin. The lungs were inflated at $20 \mathrm{~cm}$ water pressure by intratracheal infusion of $10 \%$ buffered formalin before fixation. Sections ( $5 \mu \mathrm{m}$ - thick) were stained with haematoxylin and eosin (H\&E) and observed under the light microscope. The severity of the pulmonary fibrosis was assessed based on Ashcroft's scoring system (Ashcroft et al, 1988). Briefly, all the fields of each lung section were scanned under a Leica microscope at a magnification of $\times 100$, then each field was visually graded from 0 (normal lung) to 8 (total fibrotic obliteration of the field). The mean grades obtained for all of the fields was then calculated as the visual fibrotic score. 


\section{Immunohistochemistry}

The lung sections were deparaffinised and rehydrated, then microwaved in $0.01 \mathrm{M}$ sodium citrate buffer for $15 \mathrm{~min}$ at $90^{\circ} \mathrm{C}$ to retrieve epitopes, and cooled at room temperature. An endogenous peroxidase blocking solution of $3 \%$ hydrogen peroxide was applied for $20 \mathrm{~min}$ at room temperature. After blocking the nonspecific
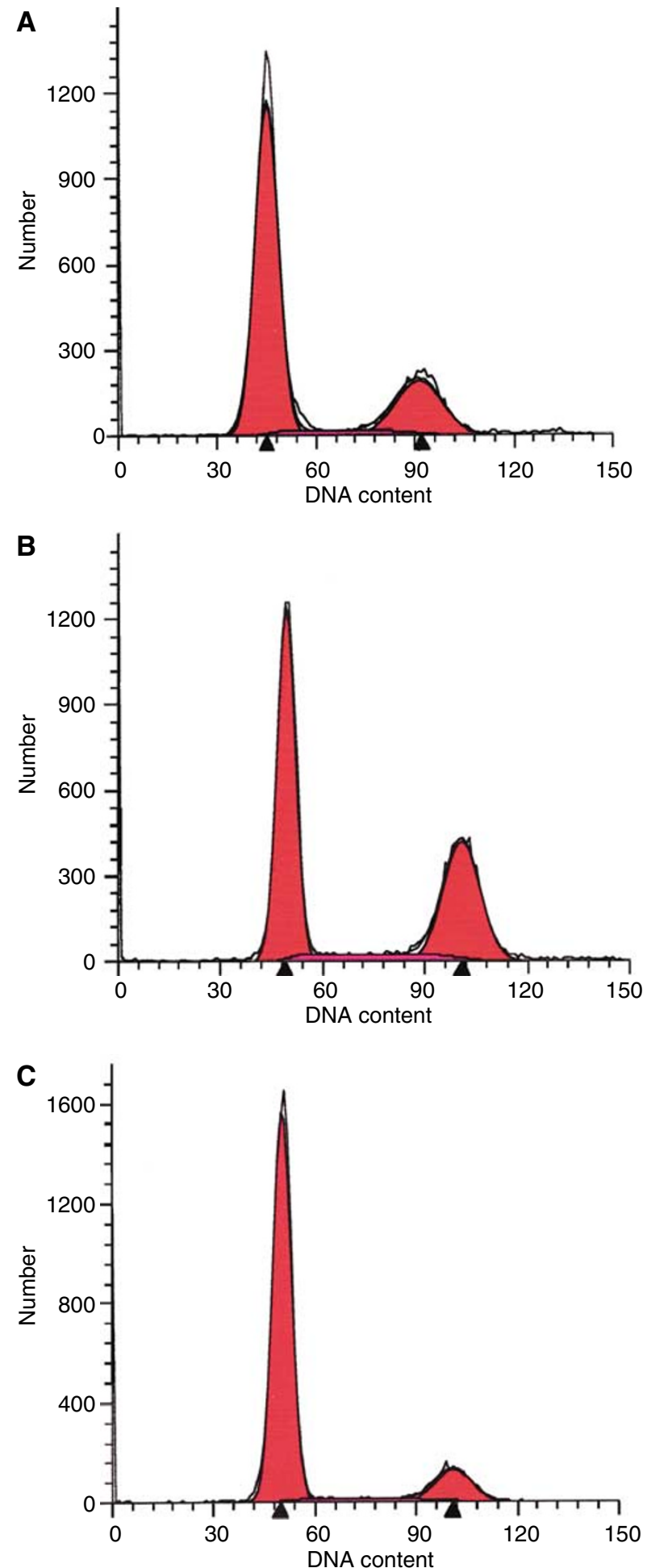

Figure I Cell cycle analysis. Cell cycle analysis of LLC tumour cells $24 \mathrm{~h}$ after PTX $(\mathbf{A})$ or NKI05 administration $(\mathbf{B})$. Untreated control cells are shown in $(\mathbf{C})$. binding sites with $2 \%$ normal goat serum, the sections were incubated with rabbit anti-mouse collagen III immunoglobulin $\mathrm{G}$ (IgG) (Chemicon International, Temecula, CA, USA) overnight at $4^{\circ} \mathrm{C}$. The sections were then washed with PBS, followed by the addition of biotin-conjugated goat anti-rabbit IgG (Vector Laboratories Inc., Burlingame, CA, USA) and incubation for $30 \mathrm{~min}$ at room temperature. The sections were then washed and incubated with horseradish-peroxidase-conjugated avidin-biotin complex (Vector Laboratories Inc., Burlingame, CA, USA) at room temperature for $30 \mathrm{~min}$, in accordance with the manufacturer's instructions (Vector Laboratories Inc.). The immunoreactions were visualised using 3,3'-diaminobenzidine as the substrate and counterstaining with haematoxylin.

\section{Statistical analysis}

Date were expressed the mean \pm s.d. Differences between the test groups were analysed by Student's $t$-test. We used Stat View (SAS Institute Inc.) statistical software. A value of $P<0.05$ was considered statistically significant.
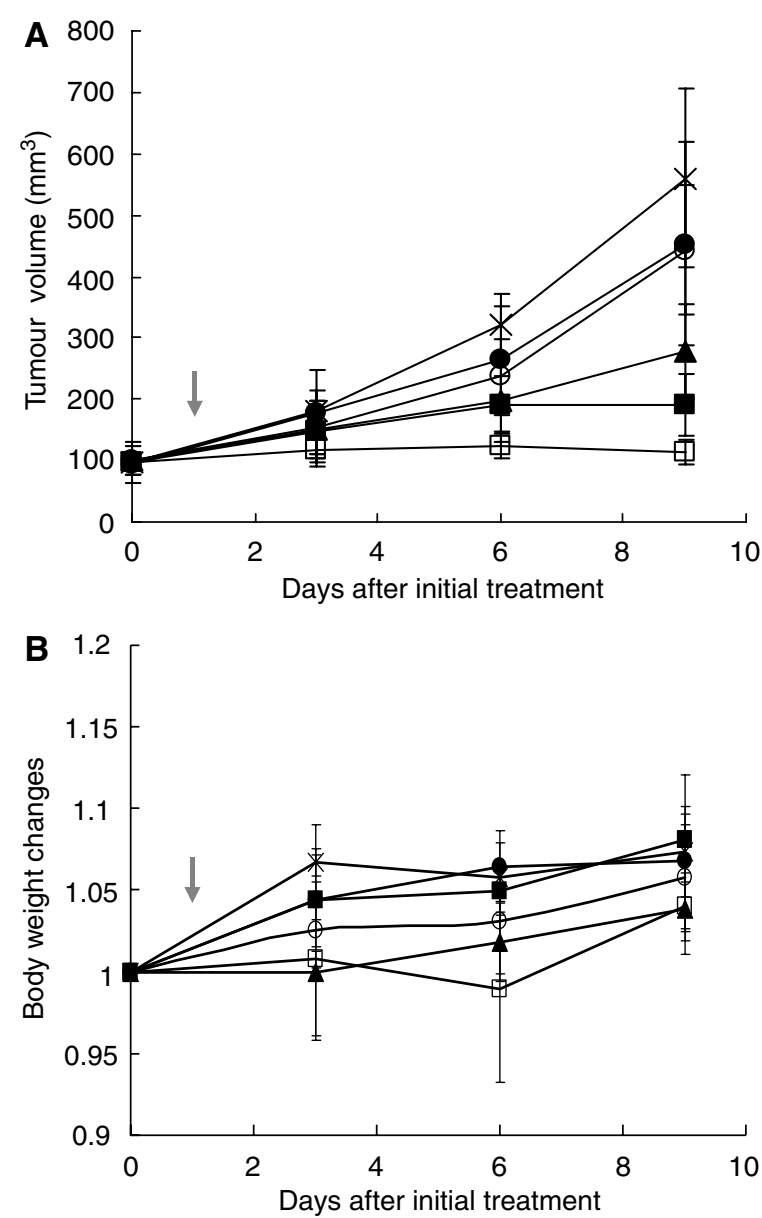

Figure 2 Antitumour activity. Changes in the LLC tumour growth rates in the mice. (A) Mice receiving TXL-alone $(\mathbf{O})$, NKI05-alone $(O)$, combined treatment with PTX and radiation ( $\mathbf{\square})$, and combined treatment with NKI05 and radiation $(\square)$ were administered a single i.v. injection of PTX or NKIO5 at the dose $45 \mathrm{mg} \mathrm{kg}^{-1}$ on day 14 after the tumour inoculation ( $=$ on day 0 after the initial treatment). After $24 \mathrm{~h}$ the drugs were administered, the mice in the radiation-alone $(\triangle)$ and the combined-treatment groups were irradiated (arrow). Mice in the control group $(x)$ were given no treatment. (B) Changes in the relative body weight. Data were derived from the same mice as those used in the present study. 
604

\section{RESULTS}

\section{Cell cycle analysis}

At $24 \mathrm{~h}$ after the administration of PTX or NK105 to the LLCtumour-bearing mice, severe cell cycle arrest at the G2/M phase was observed in the tumour cells treated with the drugs as compared with that in the control (no drug treatment) (Figure 1C). There was a tendency towards the NK105-treated LLC tumour cells (Figure 1B) showing more severe arrest at the G2/M phase than the PTX-treated cells (Figure 1A).

\section{Antitumour activity}

Decreased tumour growth rates of the LLC tumours were observed in the mice of the radiation alone, combined PTX with radiation, and combined NK105 with radiation groups. No antitumour activity was observed following treatment with either PTX or NK105 alone, because LLC is primarily a PTX-resistant tumour. Combined NK105 therapy with radiation yielded superior antitumour activity as compared to both radiation alone $(P=0.0047)$ and combined PTX therapy with radiation $(P=0.0277)$ on the day 9 after the treatment initiation (Figure 2A). No significant differences in body weight changes were noted among the groups tested (Figure 2B).

\section{Lung toxicities}

Histopathological examination of the lung sections of all the mice receiving radiation showed inflammatory cell infiltration, appear- ance of intra-alveolar macrophages, and destruction of the alveolar architecture. Major portions of the alveolar septa in the lung sections prepared from the irradiated mice showed slight thickening, although no massive structural destruction was observed (Figure 3A). On the other hand, the lung sections prepared from the control nonirradiated group showed no significant histopathological changes (Figure 3B). Ashcroft's fibrosis scores in the groups of mice that received radiation ranged from 0.975 to 1.426 , with no significant differences among the groups. The score in the control group was nearly zero. In the groups receiving radiation, the severity of lung fibrosis differed significantly among the mice within the same groups, as did the Ashcroft's scores, that is, the s.d. of the Ashcroft's scores in the mice receiving radiation was very high (Figure $3 \mathrm{C}$ ).

\section{Type III collagen deposition}

Immunohistochemical analysis of lung sections prepared from the mice receiving radiation revealed significant collagen deposition, especially in the subpleural regions, while that of lung sections prepared from the control group showed little collagen deposition. There were no significant differences among the different groups receiving radiation (Figure $3 \mathrm{D}$ ).

\section{DISCUSSION}

It is well known that PTX enhances the radiosensitivity of tumour cells by inducing cell cycle arrest at the G2/M phase, the most radiosensitive phase of the cell cycle (Terasima and Tolmach, 1963;
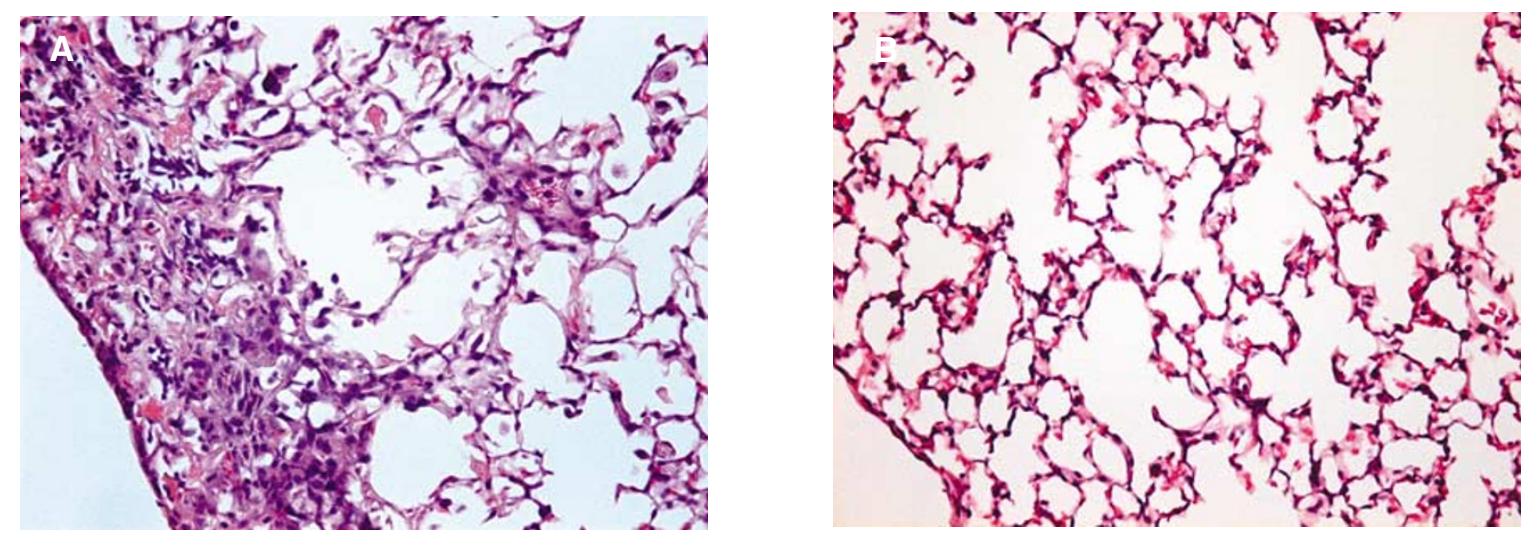

C
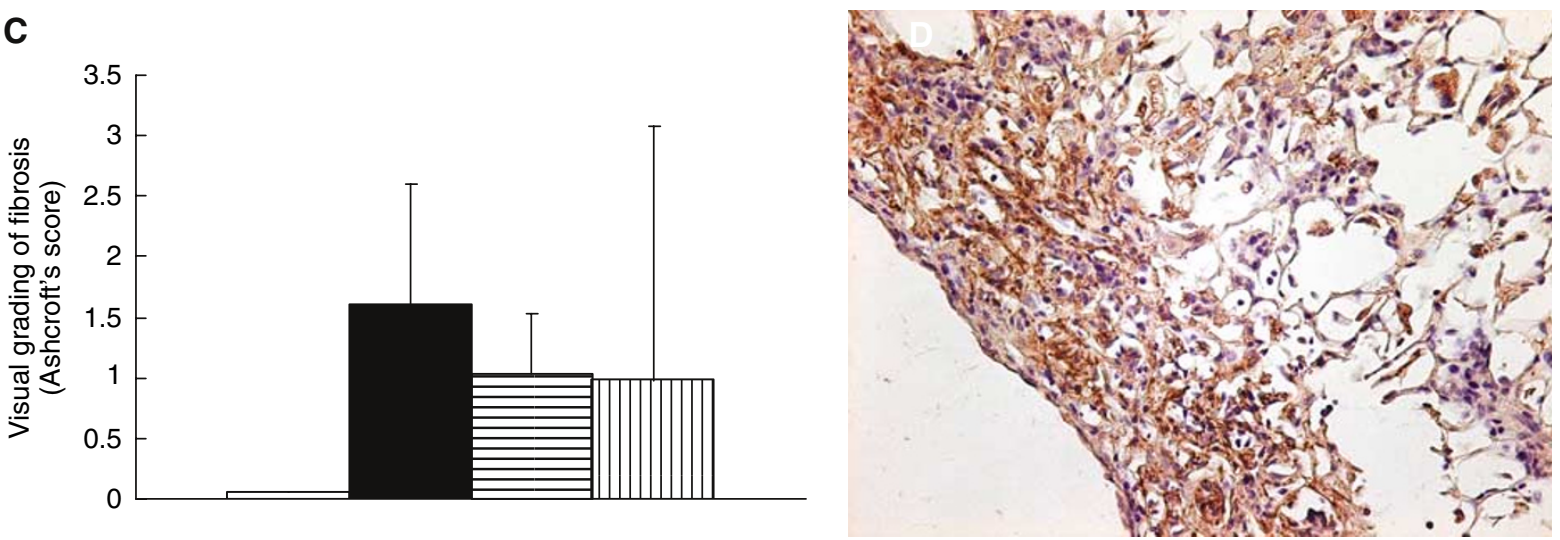

Figure 3 H\&E staining of the lungs of C57BL/6) mice surviving 36 weeks after the thoracic radiation (A) and sham radiation (B). (C) Semiquantitative analyses to estimate the severity of pulmonary fibrosis in the mice receiving sham radiation ( $\square$ ), thoracic radiation alone ( $\mathbf{\square})$, combined PTX with radiation (目), and combined NKIO5 with radiation (血). H\&E- stained lung tissue sections were assessed to estimate the severity of pulmonary fibrosis by visual grading of fibrosis (Ashcroft's score). Collagen III staining of the irradiated lungs of mice (D). 
Sinclair and Morton, 1966). Many reports have confirmed the radiosensitising effect of PTX in different cell lines (Tishler et al, 1992; Choy et al, 1993; Lokeshwar et al, 1995; Rodriguez et al, 1995), in vivo experiments (Milas et al, 1994, 1995; Cividalli et al, 1998), and in several clinical trials of combined PTX with radiation therapy according to different schedules (Dillman et al, 1990; Arriagada et al, 1991; Morton et al, 1991; Furuse et al, 1999; Sause et al, 2000; Chen et al, 2003). Chen et al (2003) examined the optimal timing of PTX treatment and irradiation in relation to the cell cycle, and recommended that radiation be given at least $5 \mathrm{~h}$ after PTX administration, because G2/M arrest of a lung cancer cell line was shown to start at $4 \mathrm{~h}$ after PTX treatment and to last for $44 \mathrm{~h}$.

In our experimental model to evaluate the antitumour activity, the tumours were irradiated $24 \mathrm{~h}$ after a single i.v. injection of PTX or NK105. No significant increase in the antitumour activity as compared with that in the control (no treatment) was observed following a single i.v. injection of either PTX or NK105 at the dose of $45 \mathrm{mg} \mathrm{kg}^{-1}$; LLC tumours are known to be primarily resistant to PTX. In fact, the $\mathrm{IC}_{50}$ of PTX against an LLC tumour cell line was shown to be $84.1 \mathrm{nM}$, which is about 10 -fold higher than that of NK105 against various cancer cell lines tested in our previous work (Hamaguchi et al, 2005). Combined NK105 therapy with radiation yielded superior antitumour activity as compared with radiation alone or combined PTX therapy with radiation. This result suggests that NK105 has a more potent radiosensitising effect than PTX. In our study, there was a tendency towards NK105treated LLC tumour cells showing more severe arrest at the G2/M phase as compared to PTX-treated cells at $24 \mathrm{~h}$ after the injection of the drugs, the timing of the radiation treatment, probably because NK105 allows a higher concentration of PTX to be maintained in the tumour than conventional PTX (Hamaguchi et al, 2005). We suppose that this is the reason why NK105 exerted more potent radiosensitising activity than PTX.

Next, we were concerned about the adverse effects of combined NK105 therapy with radiation. New micellar drugs are designed based on the idea that DDS can accumulate in the tumour selectively, while showing reduced distribution in normal tissues. We demonstrated that the incorporation of cisplatin into micelles significantly reduced the nephrotoxicity and neurotoxicity of cisplatin (Uchino et al, 2005). However, it was also shown that micelle- incorporated cisplatin caused transient liver dysfunction because it was trapped more avidly by the RES as compared to free cisplatin, even though the PEG of the outer shell of the micelle confers the so-called stealth effect.

In this study, our examination of the lung sections of mice treated with NK105 and radiation revealed that the histopathological changes such as inflammatory cell infiltration, appearance of intra-alveolar macrophages, and destruction of the alveolar architecture were induced by thoracic radiation and not by the accumulation of NK105 in the lung. There were no significant differences in the histopathological changes observed among the mice treated by $\mathrm{NK} 105$ and radiation and mice treated by radiation alone or PTX with radiation. The severity of lung fibrosis did not differ significantly among the test groups either. Although some clinical trials reported an increased incidence of pneumonitis and esophagitis following combined PTX therapy with radiation (Taghian et al, 2001; Hanna et al, 2002; Chen and Okunieff, 2004), others reported no influence on the incidence of such adverse effects (Ellerbroek et al, 2003; Yu et al, 2003). Several clinical trials and in vivo experiments have discussed the subject, however, no definitive conclusion has been arrived at (Mason et al, 1995; Choy et al, 1998; Yu et al, 2004; Kao et al, 2005). In our study, in regard to the incidence of esophagitis, there were no significant differences in the histopathological changes observed in the esophageal sections at one week after the treatment among the test groups (data not shown).

In conclusion, we demonstrated that combined NK105 chemotherapy with radiation exerts significant antitumour activity. Furthermore, the lung toxicity of this combined treatment modality was also acceptable as compared with that observed following radiation alone or combined PTX therapy with radiation. However, further studies are necessary to determine the effectiveness of NK105 in terms of its radiosensitising effect.

\section{ACKNOWLEDGEMENTS}

We thank Drs K Sugiyama and K Tsuchihara for their scientific advice and Mrs C Kanai and Mrs N Mie for their technical assistance. We are also grateful to Mrs K Shiina for her secretarial assistance. This work was supported by a Grant-in-Aid from the Ministry of Health, Labor and Welfare of Japan (Y Matsumura) and a Grant-in-Aid for Scientific Research on Priority Areas from the Ministry of Education, Culture, Sports, Science and Technology (Y Matsumura).

\section{REFERENCES}

Allen TM (1994) Long-circulating (sterically stabilized) liposomes for targeted drug delivery. Trends Pharmacol Sci 15: 215-220

Arriagada R, Le Chevalier T, Quoix E, Ruffie P, de Cremoux H, Douillard JY, Tarayre M, Pignon JP, Laplanche A (1991) ASTRO (American Society for Therapeutic Radiology and Oncology) plenary: Effect of chemotherapy on locally advanced non-small cell lung carcinoma: a randomized study of 353 patients. GETCB (Groupe d'Etude et Traitement des Cancers Bronchiques), FNCLCC (Federation Nationale des Centres de Lutte contre le Cancer) and the CEBI trialists. Int J Radiat Oncol Biol Phys 20: $1183-1190$

Ashcroft T, Simpson JM, Timbrell V (1988) Simple method of estimating severity of pulmonary fibrosis on a numerical scale. J Clin Pathol 41: 467- 470

Carney DN (1996) Chemotherapy in the management of patients with inoperable non-small cell lung cancer. Semin Oncol 23: 71-75

Chen Y, Okunieff P (2004) Radiation and third-generation chemotherapy. Hematol Oncol Clin North Am 18: 55-80

Chen Y, Pandya K, Keng PC, Johnstone D, Li J, Lee YJ, Smudzin T, Okunieff P (2003) Phase I/II clinical study of pulsed paclitaxel radiosensitization for thoracic malignancy: a therapeutic approach on the basis of preclinical research of human cancer cell lines. Clin Cancer Res 9: 969-975
Choy H, Akerley W, Safran H, Graziano S, Chung C, Williams T, Cole B, Kennedy T (1998a) Multiinstitutional phase II trial of paclitaxel, carboplatin, and concurrent radiation therapy for locally advanced non-small-cell lung cancer. J Clin Oncol 16: 3316-3322

Choy H, Devore III RF, Hande KR, Porter LL, Rosenblatt P, Yunus F, Schlabach L, Smith C, Shyr Y, Johnson DH (2000) A phase II study of paclitaxel, carboplatin, and hyperfractionated radiation therapy for locally advanced inoperable non-small-cell lung cancer (a Vanderbilt Cancer Center Affiliate Network Study). Int J Radiat Oncol Biol Phys 47: 931-937

Choy H, Rodriguez FF, Koester S, Hilsenbeck S, Von Hoff DD (1993) Investigation of taxol as a potential radiation sensitizer. Cancer 71: $3774-3778$

Choy H, Safran H, Akerley W, Graziano SL, Bogart JA, Cole BF (1998b) Phase II trial of weekly paclitaxel and concurrent radiation therapy for locally advanced non-small cell lung cancer. Clin Cancer Res 4: $1931-1936$

Cividalli A, Arcangeli G, Cruciani G, Livdi E, Cordelli E, Danesi DT (1998) Enhancement of radiation response by paclitaxel in mice according to different treatment schedules. Int J Radiat Oncol Biol Phys 40: 1163-1170

Dillman RO, Seagren SL, Propert KJ, Guerra J, Eaton WL, Perry MC, Carey RW, Frei III EF, Green MR (1990) A randomized trial of induction 
chemotherapy plus high-dose radiation $v s$ radiation alone in stage III non-small-cell lung cancer. $N$ Engl J Med 323: 940-945

Dowell JE, Sinard R, Yardley DA, Aviles V, Machtay M, Weber RS, Weinstein GS, Chalian AA, Carbone DP, Rosenthal DI (1999) Seven-week continuous-infusion paclitaxel concurrent with radiation therapy for locally advanced non-small cell lung and head and neck cancers. Semin Radiat Oncol 9: 97-101

Early Breast Cancer Trialists' Collaborative Group (2000) Favourable and unfavourable effects on long-term survival of radiotherapy for early breast cancer: an overview of the randomised trials. Early Breast Cancer Trialists' Collaborative Group. Lancet 355: 1757-1770

Ellerbroek N, Martino S, Mautner B, Tao ML, Rose C, Botnick L (2003) Breast-conserving therapy with adjuvant paclitaxel and radiation therapy: feasibility of concurrent treatment. Breast J 9: 74-78

Formenti SC, Volm M, Skinner KA, Spicer D, Cohen D, Perez E, Bettini AC, Groshen S, Gee C, Florentine B, Press M, Danenberg P, Muggia F (2003) Preoperative twice-weekly paclitaxel with concurrent radiation therapy followed by surgery and postoperative doxorubicin-based chemotherapy in locally advanced breast cancer: a phase I/II trial. J Clin Oncol 21: $864-870$

Furuse K, Fukuoka M, Kawahara M, Nishikawa H, Takada Y, Kudoh S, Katagami N, Ariyoshi Y (1999) Phase III study of concurrent $v$ s sequential thoracic radiotherapy in combination with mitomycin, vindesine, and cisplatin in unresectable stage III non-small-cell lung cancer. J Clin Oncol 17: 2692-2699

Gabizon A, Chemla M, Tzemach D, Horowitz AT, Goren D (1996) Liposome longevity and stability in circulation: effects on the in vivo delivery to tumors and therapeutic efficacy of encapsulated anthracyclines. J Drug Target 3: $391-398$

Hamaguchi T, Matsumura Y, Suzuki M, Shimizu K, Goda R, Nakamura I, Nakatomi I, Yokoyama M, Kataoka K, Kakizoe T (2005) NK105, a paclitaxel-incorporating micellar nanoparticle formulation, can extend in vivo antitumour activity and reduce the neurotoxicity of paclitaxel. $\mathrm{Br} \mathrm{J}$ Cancer 92: 1240 - 1246

Hanna YM, Baglan KL, Stromberg JS, Vicini FA, A Decker D (2002) Acute and subacute toxicity associated with concurrent adjuvant radiation therapy and paclitaxel in primary breast cancer therapy. Breast $J$ 8: $149-153$

Kao J, Conzen SD, Jaskowiak NT, Song DH, Recant W, Singh R, Masters GA, Fleming GF, Heimann R (2005) Concomitant radiation therapy and paclitaxel for unresectable locally advanced breast cancer: results from two consecutive phase I/II trials. Int J Radiat Oncol Biol Phys 61: $1045-1053$

Khayat D, Antoine EC, Coeffic D (2000) Taxol in the management of cancers of the breast and the ovary. Cancer Invest 18: 242-260

Klibanov AL, Maruyama K, Beckerleg AM, Torchilin VP, Huang L (1991) Activity of amphipathic poly(ethylene glycol) 5000 to prolong the circulation time of liposomes depends on the liposome size and is unfavorable for immunoliposome binding to target. Biochim Biophys Acta 1062: $142-148$

Klibanov AL, Maruyama K, Torchilin VP, Huang L (1990) Amphipathic polyethyleneglycols effectively prolong the circulation time of liposomes. FEBS Lett 268: 235-237

Lind PA, Marks LB, Hardenbergh PH, Clough R, Fan M, Hollis D, Hernando ML, Lucas D, Piepgrass A, Prosnitz LR (2002) Technical factors associated with radiation pneumonitis after local $+/-$ regional radiation therapy for breast cancer. Int J Radiat Oncol Biol Phys 52: $137-143$

Lokeshwar BL, Ferrell SM, Block NL (1995) Enhancement of radiation response of prostatic carcinoma by taxol: therapeutic potential for latestage malignancy. Anticancer Res 15: 93-98

Maeda H, Matsumura Y (1989) Tumoritropic and lymphotropic principles of macromolecular drugs. Crit Rev Ther Drug Carrier Syst 6: 193-210
Mason KA, Milas L, Peters LJ (1995) Effect of paclitaxel (taxol) alone and in combination with radiation on the gastrointestinal mucosa. Int J Radiat Oncol Biol Phys 32: $1381-1389$

Matsumura Y, Maeda H (1986) A new concept for macromolecular therapeutics in cancer chemotherapy: mechanism of tumoritropic accumulation of proteins and the antitumor agent smancs. Cancer Res 46: $6387-6392$

Milas L, Hunter NR, Mason KA, Kurdoglu B, Peters LJ (1994) Enhancement of tumour radioresponse of a murine mammary carcinoma by paclitaxel. Cancer Res 54: 3506-3510

Milas L, Hunter NR, Mason KA, Milross CG, Saito Y, Peters LJ (1995) Role of reoxygenation in induction of enhancement of tumour radioresponse by paclitaxel. Cancer Res 55: 3564-3568

Morton RF, Jett JR, McGinnis WL, Earle JD, Therneau TM, Krook JE, Elliott TE, Mailliard JA, Nelimark RA, Maksymiuk AW (1991) Thoracic radiation therapy alone compared with combined chemoradiotherapy for locally unresectable non-small cell lung cancer. A randomized, phase III trial. Ann Intern Med 115: 681-686

Penney DP, Rubin P (1977) Specific early fine structural changes in the lung irradiation. Int J Radiat Oncol Biol Phys 2: 1123-1132

Rodriguez M, Sevin BU, Perras J, Nguyen HN, Pham C, Steren AJ, Koechli OR, Averette HE (1995) Paclitaxel: a radiation sensitizer of human cervical cancer cells. Gynecol Oncol 57: 165-169

Rowinsky EK, Chaudhry V, Forastiere AA, Sartorius SE, Ettinger DS, Grochow LB, Lubejko BG, Cornblath DR, Donehower RC (1993) Phase I and pharmacologic study of paclitaxel and cisplatin with granulocyte colony-stimulating factor: neuromuscular toxicity is dose-limiting. J Clin Oncol 11: $2010-2020$

Rowinsky EK, Donehower RC (1995) Paclitaxel (taxol). N Engl J Med 332: $1004-1014$

Sause W, Kolesar P, Taylor SI, Johnson D, Livingston R, Komaki R, Emami B, Curran Jr W, Byhardt R, Dar AR, Turrisi III A (2000) Final results of phase III trial in regionally advanced unresectable non-small cell lung cancer: Radiation Therapy Oncology Group, Eastern Cooperative Oncology Group, and Southwest Oncology Group. Chest 117: $358-364$

Sinclair WK, Morton RA (1966) X-ray sensitivity during the cell generation cycle of cultured Chinese hamster cells. Radiat Res 29: 450-474

Taghian AG, Assaad SI, Niemierko A, Kuter I, Younger J, Schoenthaler R, Roche M, Powell SN (2001) Risk of pneumonitis in breast cancer patients treated with radiation therapy and combination chemotherapy with paclitaxel. J Natl Cancer Inst 93: 1806-1811

Terasima T, Tolmach LJ (1963) X-ray sensitivity and DNA synthesis in synchronous populations of HeLa cells. Science 140: 490-492

Tishler RB, Geard CR, Hall EJ, Schiff PB (1992) Taxol sensitizes human astrocytoma cells to radiation. Cancer Res 52: 3495-3497

Uchino H, Matsumura Y, Negishi T, Koizumi F, Hayashi T, Honda T, Nishiyama N, Kataoka K, Naito S, Kakizoe T (2005) Cisplatinincorporating polymeric micelles (NC-6004) can reduce nephrotoxicity and neurotoxicity of cisplatin in rats. Br J Cancer 93: 678-687

Weiss RB, Donehower RC, Wiernik PH, Ohnuma T, Gralla RJ, Trump DL, Baker Jr JR, Van Echo DA, Von Hoff DD, Leyland-Jones B (1990) Hypersensitivity reactions from taxol. J Clin Oncol 8: 1263-1268

Yu TK, Whitman GJ, Thames HD, Strom E, McNeese MD, Perkins GH, Schechter N, Kau S, Buzdar AU, Hortobagyi GN, Thomas E, Buchholz TA (2003) Clinically-relevant pneumonitis is not increased in breast cancer patients treated with sequential paclitaxel and radiation. Int J Radiat Oncol Biol Phys 57(2 Suppl): S127-S128

Yu TK, Whitman GJ, Thames HD, Buzdar AU, Strom EA, Perkins GH, Schechter NR, McNeese MD, Kau SW, Thomas ES, Hortobagyi GN, Buchholz TA (2004) Clinically relevant pneumonitis after sequential paclitaxel-based chemotherapy and radiotherapy in breast cancer patients. J Natl Cancer Inst 96: 1676-1681 